\title{
FETAL HYDRONEPHROSIS, A CASE REPORT AND REVIEW OF LITERATURE
}

\author{
PA SHAMSUNNAHAR ${ }^{1}$, A MOTALEB $^{2}$, B NASRIN $^{3}$, F HOSSAIN $^{4}$, S MAHMOOD $^{5}$, SA BEGUM ${ }^{6}$
}

\begin{abstract}
:
With the increasing use of antenatal sonography, fetal hydronephrosis has been reported more frequently. Hydronephrosis is one of the most commonly identified prenatal anomalies, and the severity may vary from mild to severe, depending on the underlying cause. Many cases resolve spontaneously before birth, but for those that do not, the additional prenatal evaluation can identify cases sufficiently severe to require fetal intervention to preserve renal function. The benefits of these interventions must be balanced against the significant risks of the procedures and their sequelae in long-term efficacy. Evaluation before and after birth is warranted, and factors such as cause, severity, and whether the condition is uni- or bilateral are used to formulate decisions about additional assessment and potential intervention. Here we report a case of bilateral hydronephrosis which was detected during pregnancy. After delivery right side spontaneously resolves but there was worsening of left hydronephrosis in follow up and He undergoes a left pyeloplasty at 6 months of age and does well post operatively.
\end{abstract}

Key Words - Hydronephrosis, fetus and neonates.

Introduction:

Incidence of genital - urinary anomalies ranges from 2 to 9 every 1,000 pregnancies, with a male/female ratio of $2: 1^{1}$. Prenatal US detect several pathological conditions of the urinary tract (i.e. multicystic dysplastic kidney disease, polycystic kidney disease, agencies or dysplaisa of the kidney) and other rare pathological conditions. Hydronephrosis is the most common congenital condition that is detected by prenatal ultrasound and represents $50 \%$ of all abnormalities ${ }^{2}$. In the majority of cases (63\%) prenatal

1. Dr. Parveen Akhter Shamsunnahar, Assistant Professor, Dept. of Obs \& Gynae, Bangabandhu Sheikh Mujib Medical University, Dhaka.

2. Dr. Abdul Motaleb, Associate Professor, Dept. of Medicine, Shaheed Ziaur Rahman Medical College, Bogra.

3. Dr. Begum Nasrin, Associate Professor, Dept. of Obs \& Gynae, Bangabandhu Sheikh Mujib Medical University, Dhaka.

4. Dr. Fawzia Hossain, Associate Professor, Dept. of Obs \& Gynae, Bangabandhu Sheikh Mujib Medical University, Dhaka.

5. Dr. Sharmeen Mahmood, Assistant Professor, Dept. of Obs \& Gynae, Bangabandhu Sheikh Mujib Medical University, Dhaka.

6. Dr. Shirin Akhter Begum, Associate Professor, Dept. of Obs \& Gynae, Bangabandhu Sheikh Mujib Medical University, Dhaka.

Correspondence to: Dr. Parveen Akhter Shamsunnahar, Assistant Professor, Dept. of Obs \& Gynae, Bangabandhu Sheikh Mujib Medical University. e- mail: drsurovi634@gmail.com. hydronephrosis can be associated with normal renal physiology. Frequently this finding could spontaneously return to normal during the first year of life requiring only a clinical follow up ${ }^{3}$. $50 \%$ of antenatal cases detected after 28 weeks gestation has postnatal imaging that are normal ${ }^{4}$. However in the minority of cases hydronephrosis is a severe pathologic condition that requires a surgical approach. The most frequent causes of hydronephrosis that require surgical correction are ureter-pelvic junction obstruction (11\%), vesicoureteral reflux ( $9 \%)$ and vesicoureteral junction obstruction $(4 \%)^{5}$.

Here we report a case of fetal hydronephrosis which was detected early during pregnancy and followed up after delivery.

\section{Case Report}

A new born male infant is noted to have bilateral hydronephrosis on prenatal ultrasound at 31 weeks of pregnancy. At 36 weeks of pregnancy there was worsening of left renal hydronephrosis $(12.5 \mathrm{~mm})$ with no dilation of ureter. At 3 days of age renal and bladder ultrasound shows a moderately severe left renal 
hydronephrosis with no dilation of ureter and normal right kidney. The bladder is normal. A voiding cystourethrogram is obtained at 6 weeks of age which shows no evidence of vesicoureteral reflux, and no posterior urethral valves. Urinalysis, complete blood count, electrolytes, BUN, and creatinine are normal.

The patient is placed on surveillance with serial renal ultrasounds and renal scans for the next 6 months. At 6 months of age, he develops left sided abdominal pain, nausea and vomiting, without fever or chills. A renal ultrasound shows worsening left hydronephrosis.

He undergoes a left pyeloplasty at 6 months of age and does well post operatively.

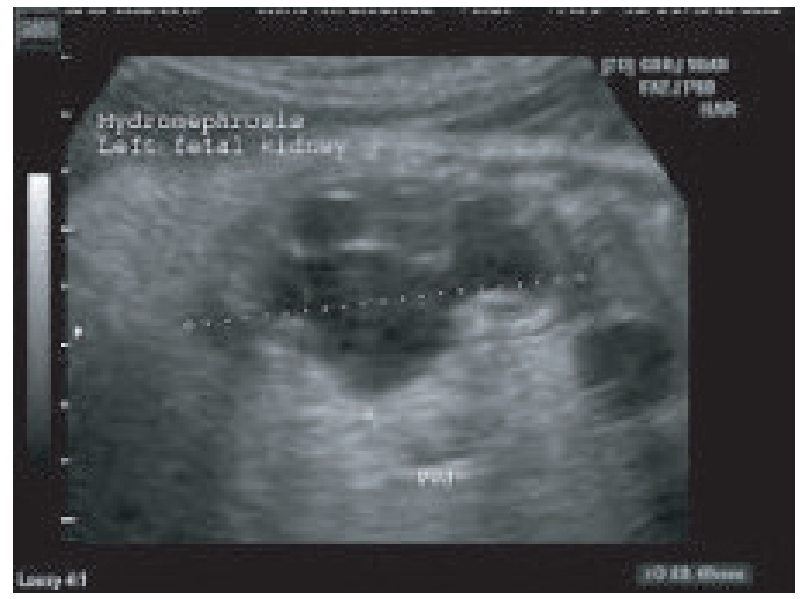

Fig.-1: Left sided fetal hydronephrosis.

\section{Discussion:}

Ureteropelvic junction obstruction is the most common cause of congenital hydronephrosis. USG or IVP will show a dilated renal pelvis, and calyces without ureteral dilation. Diuretic renography/renal scan will show an obstructive pattern (prolonged washout half time). Vesicoureteral reflux may be present in some children with UPJ obstruction ${ }^{6}$.

Ureteropelvic junction obstruction is the second most common cause of congenital hydronephrosis. Hydronephrosis is noted, along with associated ureteral dilation on renal USG and/or IVP. Renal scan may show an obstructive pattern. Dilated ureter (megaureters) is divided into three primary categories: refluxing megaureters, obstructed megaureters, and non - obstructed, non-refluxing megaureters.

Posterior urethral valves are the most common cause of lower urinary tract obstruction and occur in males. The prenatal USG may show hydroureteronephrosis, bladder thickening and oligohydramnios. The newborn physical exam may reveal a palpable distended bladder, a palpable prostate on rectal exam, poor urinary stream, and signs and symptoms of renal and pulmonary insufficiency. Renal USG shows hydronephrosis and a thickened bladder. Voiding cystourethrogram (VCUG) is diagnostic for posterior urethral valves. There is associated reflux in $30 \%$ of patients ${ }^{7}$.

In females, the most common cause of anatomic bladder outlet obstruction is an ureterocele that has prolapsed into urethra (urethral prolapse may resemble a large doughnut shaped mass in the perineum). $90 \%$ of cases are associated with the upper pole of a complete duplicated collecting system ${ }^{8}$. This condition has also been observed in males. Renal ultrasound may show findings similar to those found with posterior urethral valves, as will VCUG and renal scan. The renal USG and/or VCUG will also clearly show the ureterocele.

Primary vesicoureteral reflux may present initially as hydronephrosis in the newborn. VCUG is diagnostic, and renal scan shows a non obstructive pattern. It tends to be of higher grade and with a male predominance when presenting in newborn period ${ }^{9}$.

Other causes of hydronephrosis or apparent hydronephrosis, are the multicystic, dysplastic kidney, ectopic ureter, megacalycosis, simple renal cyst, urachal cyst, ovarian cyst, hydrocolops, sacrococcygeal teratoma, bowel duplication, duodenal atresia, anterior meningocele, and the prune belly syndrome ${ }^{2}$.

Ureteropelvic junction obstruction repair (open pyeloplasty) is recommended when there is the morphological appearance of UPJ obstruction on US or IVP no evidence of distal ureteral distension, and renal function depressed to less than $35 \%$ of total renal function. Neonates with better than $25 \%$ renal function are followed with repeat scans at 3 to 6 months, then at 12 months of age, and surgery is indicated only when there is clear deterioration in renal are followed with repeat function (1). 75 to $85 \%$ of infants followed in this manner with observation did not require surgery ${ }^{10}$. Most patients being followed with observation received antibiotic prophylaxis.

Ureterovesical junction obstruction/megaureters in the newborn can be managed with observation (with serial US and renal scans) and antibiotic prophylaxis, in those whose renal function is greater than $35 \%$ (1). 
Indications for surgical repair (open ureteral reimplant sometimes with tapering), include deterioration of renal function, breakthrough pyelonephritis, and pain or calculus formation ${ }^{8}$. When an ureterocele is present, the best initial management is endoscopic incision of the ureterocele .

Posterior urethral valves should be treated in the neonatal period. Treatment is centered on securing adequate drainage of the urinary tract, initially by placement of a urinary catheter and later, by primary cystoscopic ablation of the valves, vesicostomy, or upper urinary tract division. The long-term outcome is dependent upon the degree should be treated with anticholinergics, alpha blockers, and clean intermittent catheterization, as indicated 7,8 .

Fetuses with mild to moderate hydronephrosis are generally observed prenatally. Although there are some centers that treat severe hydronephrosis prenatally related to obstructive uropathy, this is very controversial. The consensus is that intrauterine intervention should be considered only if persistent or progressive oligohydramnios develops in a fetus with a normal karyotype, there are no other life threatening anomalies, and fetal immaturity that precludes delivery ${ }^{4,7}$. These procedures should be performed at tertiary referral centers with extensive experiences with fetal surgery.

\section{Conclusion:}

The widespread use of obstetrical ultrasound has resulted in the detection of antenatal hydronephrosis as a common presentation of congenital renal, ureteral, bladder and urethral anomalies. Neonatal evaluation and treatment of these congenital urinary anomalies allows the preservation of renal function, the relief of obstruction and reflux, the elimination of infection, and the preservation of urinary continence, to a much greater degree than was possible prior to the advent of prenatal USG. Patients with hydronephrosis and/or reflux have an excellent prognosis today.

\section{References:}

1. Pates JA, Dashe JS. Prenatal diagnosis and management of hydronephrosis. Early Hum dev 2006; 82:3-8.

2. Blythe B, Snyder HM, Duckett JW. Antenatal Diagnostic and Subsequent Management of Hydronephrosis. J Urology 1993;149(4):693-398.

3. Belarmino JM, Kogan BA. Management of neonatal hydronephrosis. Early Hum dev 2006; 82:9-14.

4. Copten DE. Prenatal Management of Hydronephrosis. AUA Update Series, 2000. Volume XIX, Lesson 17, pp. 130-135.

5. Ismaili K, Avni FE, Wissing KM, Hall M. Brussels Free University Perinatal Nephrology Study Group. Long - term clinical outcome of infants with mild and moderate fetal pyelectasis: validation of neonatal ultrasound as a screening tool to detect significant nephrouropathies. J Pediatr 2004;144:759-65.

6. Kramer SA. Chapter 25- Vesicoureteral Reflux. In:Beiman, AB, King LR, Kramer SA. Clinical Pediatric Urology, $4^{\text {th }}$ Edition, 2002, London, Martin Dunitz, Ltd., pp. 749-810.

7. Vogt BA, Avner ED. Chapter 49-The kidney and urinary tract. In: Hanno PM, Malkowicz SB, Wein Aj (eds). Clinical Manual of Urology, third Edition. 2002, St. Louis: Mosby, Inc., pp. 1517-1536.

8. Cilento BG,j, Retik AB. Recognizing and Treating UreteralAnomalies. Contemp Uro 2000;12(6):12-31.

9. Kramer SA. Chapter 25-Vesicoureteral Reflux, In: Beiman, AB, King LR, Kramer SA. Clinical Pediatric Urology, $4^{\text {th }}$ Edition. 2002, London, Martin Dunitz, Ltd., pp. 749-810.

10. Palmer LS, et. al. Surgery Versus Observation for Managing Obstructive Grade 3 to 4 Unilateral Hydronephrosis: Areport from the society for Fetal Urology. J Urol 1998;159(1): 222-228.

11. Kropp BP, Cheng EY. Management options for UPJ Obstruction in Children. Contemp Urol 1998;10(5):15-31A. 